\title{
CFD analysis of partial slip effect on the performance of hydrodynamic lubricated journal bearings
}

\author{
Muchammad $^{1,2,}$, Bambang Yunianto ${ }^{1}$, Mohammad Tauviqirrahman ${ }^{1}$, Widhi Ahmad \\ Wicaksono ${ }^{1}$, and Jamari ${ }^{1}$ \\ ${ }^{1}$ Laboratory for Engineering Design and Tribology, Department of Mechanical Engineering, \\ University of Diponegoro, 50275 Semarang, Indonesia. \\ ${ }^{2}$ Laboratory for Surface Technology and Tribology, Faculty of Engineering Technology, University \\ of Twente, Netherlands. Drienerloolan 5, Postbus 217, 7500 AE, Enschede, The Netherlands.
}

\begin{abstract}
Slip modification of the lubricated bearing such hydrophobic coating has proven to improve the hydrodynamic performance. The present paper investigates the effect of partial slip on the journal bearing performance using computational fluid dynamic (CFD) approach. The eccentricity ratio and the placement of slip area are of particular interest. It was shown that the partial slip placement on the convergent region of the bearing generally improves the hydrodynamic performance lubrication by increasing load support. It was also found that introducing partial slip on the divergent area decreases the lubrication performance of journal bearing.
\end{abstract}

\section{Introduction}

An artificial slip surface is an effective approach to increase the tribological performance of lubricated mechanical components. The use of an artificial slip surface has become popular with respect to lubrication, it gives a better tribological performance. It is known that introducing slip surfaces significantly can affect friction and load support of bearings [1-7]. Two deterministic slip surface modes are used currently; homogeneous slip surface (i.e. slip applied over the whole surface) [1-4] and partial slip (i.e. surface consisting of slip and noslip areas) [1-7].

How to control the wall slip was one of the challenging research questions in recent investigations. Several researchers such as Salant and Fortier [5], Ma et al. [6], Wu et. al. [7], have explored the behavior of the sliding contact using an optimized slip zone with respect to load support. The results of all these investigations show the existence of a lift force (load support) even there is no wedge effect (two parallel sliding surfaces) using such artificial slip zone.

The effects of artificial slip surface on the tribological performance have been analyzed numerically by many researchers such as Aurelian et al. [3], Salant et al. [4], Wu et.al [6] and Brajdic-Mitidieri et al. [7]. There are two approaches for the investigation of artificial

*Corresponding author: m_mad5373@yahoo.com 
slip surfaces, i.e. using the CFD models based on Navier-Stokes [7] and using Reynolds. $[3-4,6]$. It was also confirmed that using numerical simulation the introduction of partial slip on the stationary surface of a parallel slider leads to a net pressure build-up and hydrodynamic load support and friction reduction.

The present paper explores the effect of the placement of the wall slip on the journal bearing performance using CFD model based on Navier-Stokes. In particular, the investigation is focused on the generation of the pressure distribution and the load support. The variation of slip placement is a main of particular interest.

\section{Methodology}

\subsection{CFD Model}

Figure 1 shows the schematic and details partial slip placement on the journal bearing. The shaft receives an external load and spins on housing, while the gap between shaft and housing contains lubricant. The main characteristics of the bearing and the lubricant properties studied are presented in Table 1. Hydrodynamic lubrication performance especially load support is the main focus of this research. For this case, the partial slip is given on the convergent and divergent areas to improve the hydrodynamic performance. The slip region is located on the region with interval by every 30 degrees both on the convergent or divergent side. In addition, the effect of the eccentricity ratio of the performance is also a particular interest. In this research, the eccentricity ratio of 0.2 and 0.8 are used.
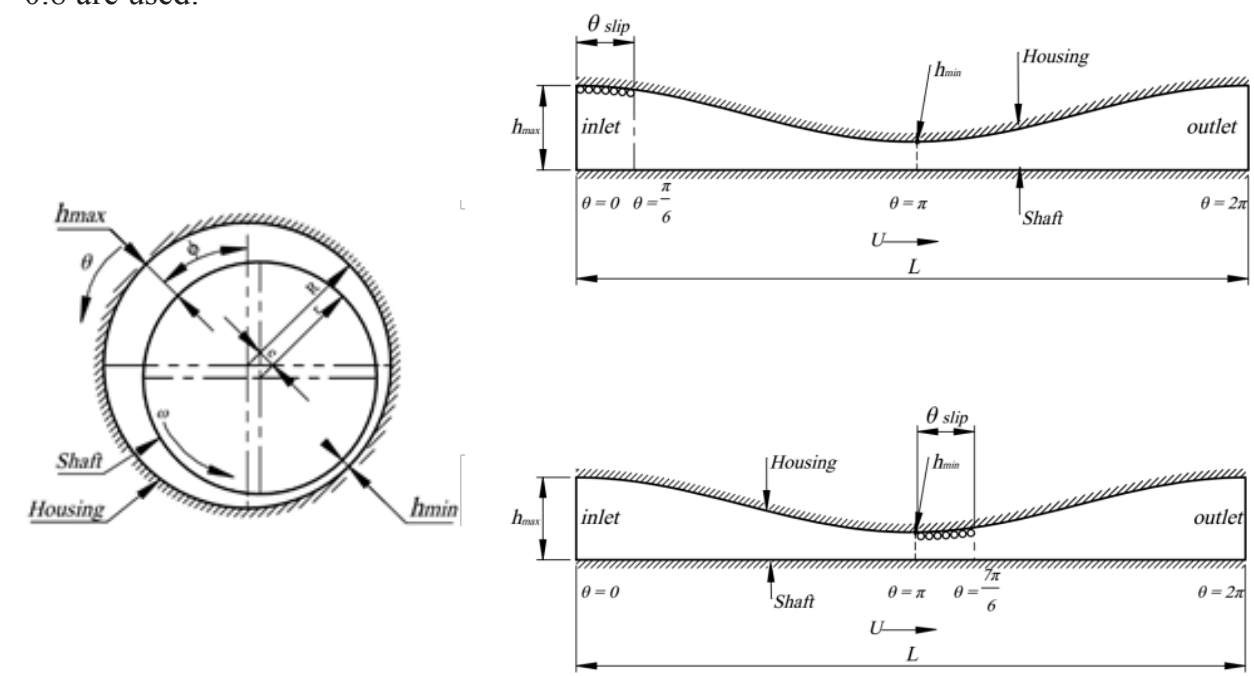

Fig. 1. Schematic of slip in journal bearing. 
Table 1. The main parameters of the journal bearing.

\begin{tabular}{|c|c|c|}
\hline Parameter & Data Setting & Unit \\
\hline Shaft radius, $r$ & 39.94 & $\mathrm{~mm}$ \\
\hline Housing radius, $R$ & 40 & $\mathrm{~mm}$ \\
\hline Radial clearance, $C$ & 0.06 & $\mathrm{~mm}$ \\
\hline The ratio of eccentricity, $\varepsilon$ & $0.2 ; 0.8$ & - \\
\hline Eccentricity, $e$ & $0 . .012 ; 0.048$ & $\mathrm{~mm}$ \\
\hline Shaft rotation, $\omega$ & 1000 & $\mathrm{rpm}$ \\
\hline Lubricant density, $\rho$ & 998.2 & $\mathrm{~kg} / \mathrm{m}^{3}$ \\
\hline Lubricant viscosity, $\mu$ & 0.001 & $\mathrm{~kg} / \mathrm{ms}$ \\
\hline
\end{tabular}

\subsection{Theory}

In the present study, the lubrication problem is solved by the Navier-Stokes equation and continuity equations. The Navier-Stokes (N-S) equations are solved over the domain using a finite-volume method with the commercial CFD software package FLUENT®. The Navier-Stokes and the continuity equations can be expressed, respectively.

$$
\begin{gathered}
\rho \frac{D u_{i}}{D t}=-\frac{\partial p}{\partial x_{i}}+\rho G_{i}+\frac{\partial}{\partial x_{j}}\left[2 \eta e_{i j}-\frac{2}{3} \eta\left(\nabla . u_{i}\right) \delta i j\right] \\
\nabla \bullet u=0
\end{gathered}
$$

In the present study, there are two variations of partial slip placement, i.e. firstly, a slip is placed on the convergent and secondly, slip is located on divergent areas. The slip positions are given at each angle length of 30 degrees on the convergent and divergent area of the journal bearing. A mesh number of about 100,000 - 120,000 nodes for the computational domain was utilized depending on the artificial slip surfaces. It should be noted that the meshing process for textured surfaces has been checked to ensure grid independent results.

\section{Results and discussions}

Figure 2 depicts the load support profile as a function of partial slip on the convergent area for the case of eccentricity ratio of 0.2 and 0.8 , respectively. For the case of eccentricity ratio of 0.2 , the maximum load support is $8.08 \mathrm{kN}$ on a partial slip of $0-90$ degrees. The minimum load support is $3.49 \mathrm{kN}$ on the partial slip area of $150-180$ degrees. This condition is very interesting because giving slip in a certain area can increase and decrease the load support. The load support on no-slip condition is 4.19 . Therefore, giving the partial slip at 0-90 degrees improves the load support of $92.84 \%$. Otherwise, by giving partial slip at 150-180 degrees decreases the load support of $-16.70 \%$. Figure $2 \mathrm{a}$ also shows partial slip at the end convergent area will decrease the load support. On the eccentricity ratio 0.8 , by giving partial slip on the beginning convergent areas decrease load support. Otherwise, 
increasing support load occurs when the partial slip is applied on the end convergent region The maximum load support is $35.23 \mathrm{kN}$ on the partial slip is 120-180 degrees. The minimum load support is $21.87 \mathrm{kN}$, while the load support on the no-slip condition is 27.19 $\mathrm{kN}$. On this condition, the maximum increasing load support is $29.57 \%$ and the minimum decreasing load support is $24.32 \%$.

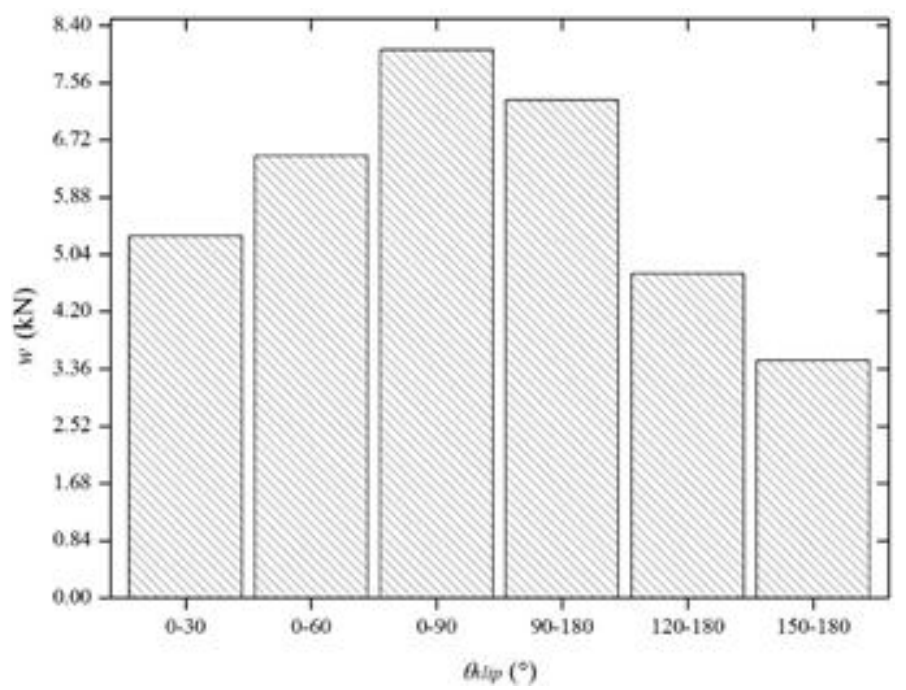

(a)

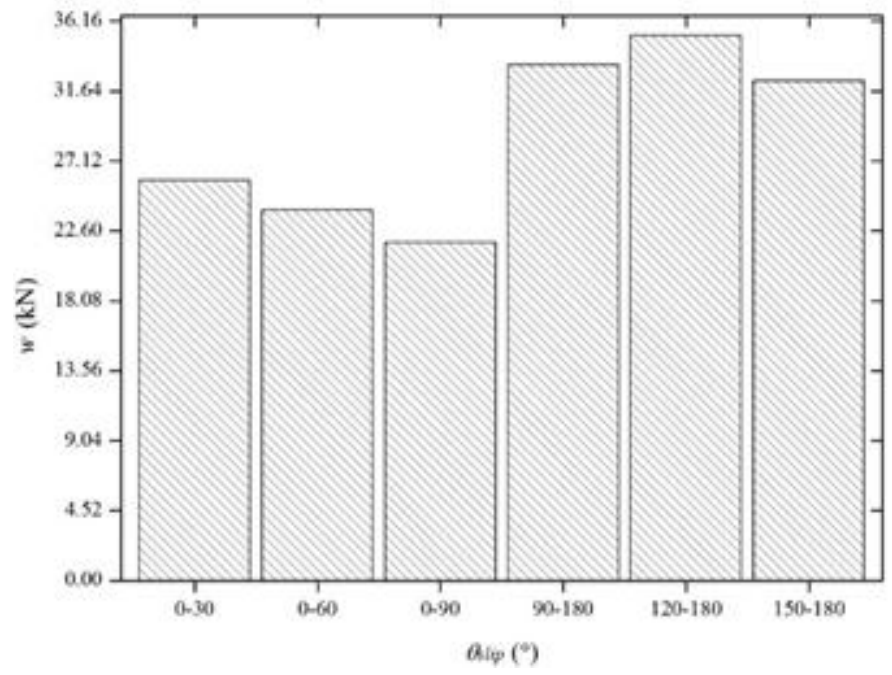

(b)

Fig. 2. The load support as a function of partial slip on convergent areas (a) The eccentricity ratio 0.2 (b) The eccentricity ratio 0.8 .

Figure 3 shows the load support as a function of partial slip on the divergent area. On the eccentricity ratio of 0.2 and 0.8 , the load support of no-slip condition is $4.19 \mathrm{kN}$ and 27.19 $\mathrm{kN}$ respectively. Giving the partial slips on the divergent area decreases the load support for all conditions and all eccentricity ratio values considered here. For the eccentricity ratio of 
0.2 , the minimum load support is $0.81 \mathrm{kN}$ with the partial slip area is $180-270$ degrees, It decreases by $417.28 \%$. For the case of the eccentricity ratio of 0.8 , the minimum load support is $19.81 \mathrm{kN}$, which means that it decreases by $37.25 \%$. Therefore, it is not advisable to provide the partial slip on divergent region of the bearing.

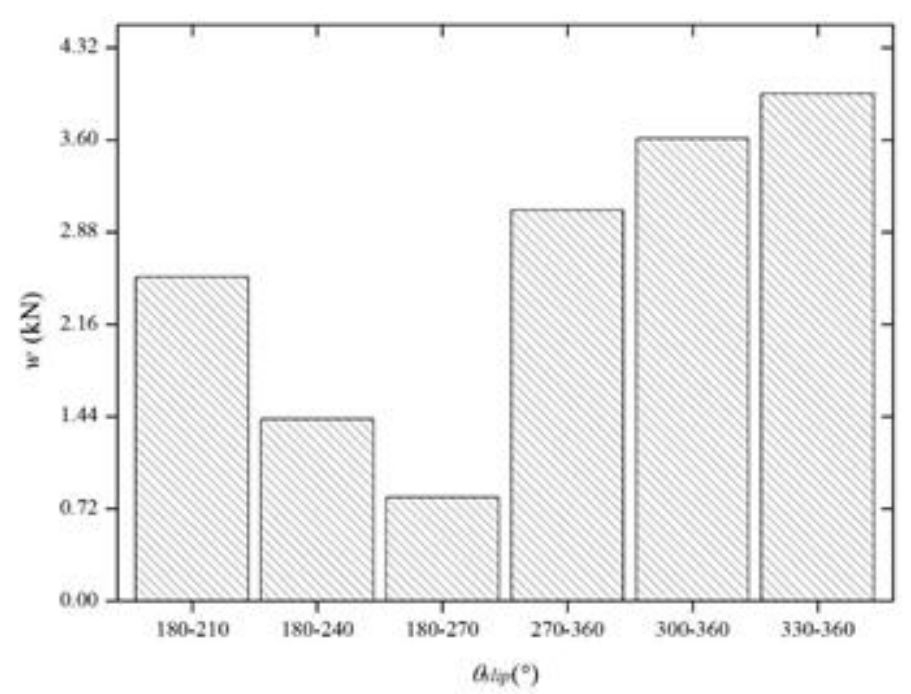

(a)

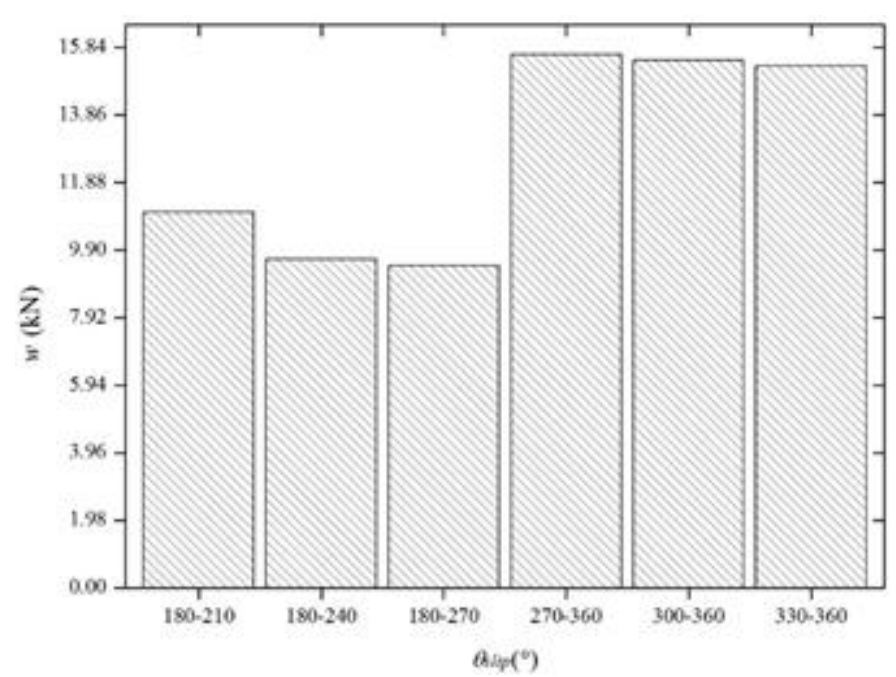

(b)

Fig. 3. The load support as a function of partial slip on divergent areas (a) The eccentricity ratio 0.2 (b) The eccentricity ratio 0.8 .

\section{Conclusions}

This paper is focused on the possibility of slip effect on the convergent and divergent area of journal bearing. The CFD model based on Navier-Stokes in journal bearing was presented and the effect of the boundary slip on the hydrodynamic performance (load 
support and friction) has been analysed. Based on the explanation discussed earlier, the conclusions can be drawn as follows:

1. For the case of the eccentricity ratio of 0.2 and 0.8 , the partial slip on the convergent area is able to increase the load support of the journal bearing.

2. Partial slip on divergent area is not recommended as it decreases the load support when compared to the no-slip conditions for all values of eccentricity ratio.

\section{References}

1. J.H. Choo, R.P. Glovnea, A.K. Forrest, H.A. Spikes, ASME J. Tribol. 129, 611 (2007)

2. F. Guo, P.L. Wong, Proc. Inst. Mech. Eng., Part J: J. Eng. Tribol. 48, 43 (2006)

3. F. Aurelian, M. Patrick, H. Mohamed, Tribol. Int. 44, 868 (2011)

4. R.F. Salant, A.E. Fortier, Tribol. Trans. 47, 328 (2004)

5. G.J. Ma, C.W. Wu, P. Zhou, Sci. China Phys. Mech. 50, 321 (2007)

6. C.W. Wu, G.J. Ma, P. Zhou, ASME J. Tribol. 128, 904 (2006)

7. P. Brajdic-Mitidieri, A.D. Gosman, E. Loannides, H.A. Spikes, ASME J. Tribol. 127, 803 (2005) 